\title{
Ambenonium Chloride Tetrahydrate
}

National Cancer Institute

\section{Source}

National Cancer Institute. Ambenonium Chloride Tetrahydrate. NCI Thesaurus. Code C79523.

The tetrahydrate and chloride salt form of ambenonium, a bisquaternary ammonium alcohol with parasympathomimetic activity. The positive charge of ambenonium allows it to act as an acetylcholinesterase inhibitor by binding to the anionic site at the reactive center of acetylcholinesterase, preventing the breakdown of acetylcholine and producing an indirect cholinomimetic effect at both nicotinic and muscarinic receptors.

Ambenonium also has direct agonist activity at nicotinic receptors, potentiating the cholinomimetic effect at the neuromuscular junction. 